\title{
Non-Relative Value Unit-Generating Activities Represent One-Fifth of Academic Neuroradiologist Productivity
}

\author{
(D) M. Wintermark, (D) M. Zeineh, (D). Zaharchuk, (D) Arivastava, and DN. Fischbein
}

\begin{abstract}
BACKGROUND AND PURPOSE: A neuroradiologist's activity includes many tasks beyond interpreting relative value unit-generating imaging studies. Our aim was to test a simple method to record and quantify the non-relative value unit-generating clinical activity represented by consults and clinical conferences, including tumor boards.
\end{abstract}

MATERIALS AND METHODS: Four full-time neuroradiologists, working an average of $50 \%$ clinical and $50 \%$ academic activity, systematically recorded all the non-relative value unit-generating consults and conferences in which they were involved during 3 months by using a simple, Web-based, computer-based application accessible from smartphones, tablets, or computers. The number and type of imaging studies they interpreted during the same period and the associated relative value units were extracted from our billing system.

RESULTS: During 3 months, the 4 neuroradiologists working an average of 50\% clinical activity interpreted 4241 relative value unitgenerating imaging studies, representing 8152 work relative value units. During the same period, they recorded 792 non-relative value unit-generating study reviews as part of consults and conferences (not including reading room consults), representing $19 \%$ of the interpreted relative value unit-generating imaging studies.

CONCLUSIONS: We propose a simple Web-based smartphone app to record and quantify non-relative value unit-generating activities including consults, clinical conferences, and tumor boards. The quantification of non-relative value unit-generating activities is paramount in this time of a paradigm shift from volume to value. It also represents an important tool for determining staffing levels, which cannot be performed on the basis of relative value unit only, considering the importance of time spent by radiologists on non-relative value unit-generating activities. It may also influence payment models from medical centers to radiology departments or practices.

ABBREVIATION: RVU = relative value unit

$\mathbf{R}$

adiologists' productivity is typically evaluated on the basis of the number of imaging studies they interpret or procedures they perform. The amount of work input for each imaging study or procedure is captured by the professional component of a relative value unit (RVU). The professional component work RVU is currently the accepted basis for measuring work output by radiologists. ${ }^{1}$

In January 2015, 2 ambitious goals were set by the Department of Health and Human Services that will significantly impact radiology: One-half of all Medicare payment to hospitals and physicians will be based on alternative payment models (ie, Account-

Received October 6, 2015; accepted after revision December 14.

From the Departments of Radiology (M.W., M.Z., G.Z., N.F.), Neuroradiology Section, and Radiology (A.S.), Stanford University, Stanford, California.

Please address correspondence to Max Wintermark, MD, MAS, MBA, Department of Radiology, Stanford University School of Medicine, 300 Pasteur Dr, S047, Stanford, CA 94305; e-mail: max.wintermark@gmail.com; @StanfordNRAD

http://dx.doi.org/10.3174/ajnr.A4701 able Care Organizations) by 2018; and $85 \%$ of all fee-for-service payments will be tied to quality or value by 2016 , with $90 \%$ by 2018. ${ }^{2}$ Shifting from fee-for-service reimbursement in Medicare to a pay-for-performance model has long been an aspiration of the Department of Health and Human Services. However, this is the first time the Department of Health and Human Services has set explicit numeric goals for alternative payment models and value-based payments. ${ }^{3}$ Radiology has much to do to prepare for the transition from the current fee-for-service payment schedule to new value-based reimbursement systems because it has historically not measured its added value to patient care and not communicated it in easily understood terms to all stakeholders. This includes quantifying all activities in which radiologists are engaged that clearly add value to patient care but do not generate RVUs.

One of the key non-RVU-generating activities in which neuroradiologists engage with their referring clinical colleagues is providing expertise during consults and a variety of clinical con- 


\begin{tabular}{|l|}
\hline Neuroradiologists Initials \\
\hline Number of studies to be recorded \\
\hline List all patient accession number(s \\
\hline Check all that apply \\
$\square$ CT $\square$ MRI $\square$ PET \\
Check all that apply \\
$\square$ Brain $\square$ Neck $\square$ Spine \\
Mutually Exclusive \\
O l-on-1 \\
$\bigcirc$ Conference \\
EPIC Email/Phone \\
Requesting Service \\
Neurology \\
Neurosurgery \\
Traumatrics \\
Medicine \\
Radiation Oncology \\
\hline Other
\end{tabular}

FIG 1. User interface of our simple, Web-based smartphone app to record our non-RVU-generating consults.

ferences, including tumor boards. While most radiologists are involved in such activities, the exact effort represented by this activity has typically not been quantified; this feature has made it difficult to assess the exact value of the activity. In this study, we propose a simple method to quantify the activity represented by consults and clinical conferences, including tumor boards, and to estimate the radiologist's time consumed.

\section{MATERIALS AND METHODS}

We designed a simple, Web-based app (Fig 1) by using REDcap software (http://project-redcap.org/). This app was accessible from smartphones, tablets, or computers and allowed radiologists, in a few clicks and several seconds, to record the following information for each consult or clinical conference: radiologist's initials, number of studies reviewed in that encounter, technique (CT, MR imaging, PET), anatomic region (brain, neck, spine), type of encounter (1-on-1 in-person consultations, e-mail/phone consultations, consultation request through the electronic medical record, conferences), and requesting service (Neurology, Neurosurgery, Otolaryngology Head and Neck Surgery, Neuro-Oncology, Pediatrics, Psychiatry, Trauma, Medicine, Radiation Oncology, Emergency Department, other). Tumor boards were counted under "conferences," but a number of clinical conferences were given that were not tumor boards (epilepsy conference, stroke conference, and so forth). Only the cases actually shown during conferences were counted.

Four full-time neuroradiologists, working an average of 50\% clinical and 50\% nonclinical activities, systematically recorded all non-RVU-generating consults and conferences for 3 months. The number and type of imaging studies they interpreted during the same period and the associated RVUs were extracted from our billing system. The 50\% nonclinical activity encompassed funded research, teaching, and administrative activities.

Of note, we did not count reading room consults (ie, the phone calls, consults, and communication of results for imaging studies being interpreted in the reading room). If an inpatient study was reviewed after it was interpreted by a neuroradiologist different from the one who signed the report for this study, it was included in the non-RVU count. The non-RVU count included non-RVU-generating consults that occurred during clinical and academic days and off-hours.

\section{RESULTS}

During 3 months (January-March 2015), the 4 neuroradiologists working an average of $50 \%$ clinical activity (4 times 0.5 clinical full-time equivalents or 2 clinical full-time equivalents) and interpreted 4241 RVU-generating imaging studies, representing 8152 work RVUs. During the same period, they recorded 792 nonRVU-generating study reviews as part of consults and conferences. This represented 19\% (792/4241) of the number of RVUgenerating imaging studies (Table 1) or an equivalent of 1549 work RVUs. The 19\% was relatively constant for each of the 4 neuroradiologists and indicated that the neuroradiologists with less academic time and reading more RVUs also performed more non-RVU-generating consults and conferences. If we used the 2013 Medical Group Management Association statistics (median salary per RVU $=\$ 53.34$, http://www.mgma.com/industry-data/ all-data-resources/benchmarking-tools-from-mgma-surveys), this translated into $\$ 82,617$ for 2 clinical full-time equivalents or $\$ 41,308$ per year for 1 clinical full-time equivalent. If we used the 2013 Association of Administrators in Academic Radiology statistics (median salary per RVU $=\$ 45.16$ ), this translated into $\$ 69,953$ for 2 clinical full-time equivalents or $\$ 34,976$ per year for 1 clinical full-time equivalent. Again, this did not include the reading room consults as explained above because these were considered the postimaging acquisition component of the RVUs associated with these imaging studies rather than non-RVU-generating activities.

Slightly more than half of non-RVU-generating encounters were clinical working conferences, including tumor boards (Table 2 ). The rest represented a mix of 1-on-1 encounters, e-mails, phone calls, text messages, pages, and electronic medical record consults, in which a physician would contact a specific radiologist and request image review and discussion. Sixty-eight percent of the conferences and consults involved individuals who were already patients of our institution; 32\% involved outside imaging studies. PET studies are typically read by the nuclear medicine department, but the non-RVU-generating consults and conferences included $8 \%$ of PET studies. 
Table 1: Modality and anatomic region for RVU-generating and non-RVU-generating imaging studies

\begin{tabular}{|c|c|c|c|c|}
\hline \multicolumn{2}{|c|}{$\begin{array}{l}\text { RVU- } \\
\text { Generating } \\
\text { Activity }\end{array}$} & \multicolumn{2}{|c|}{$\begin{array}{l}\text { Non-RVU- } \\
\text { Generating } \\
\text { Activity }\end{array}$} & \multirow{2}{*}{$\begin{array}{c}\begin{array}{c}\text { RVU/Non- } \\
\text { RVU Ratio }\end{array} \\
19 \%\end{array}$} \\
\hline$n=4241$ & Studies & $n=792$ & Studies & \\
\hline 2271 (55\%) & CT & $251(32 \%)$ & $\mathrm{CT}$ & $11 \%$ \\
\hline 1970 (45\%) & MRI & $474(60 \%)$ & MRI & $24 \%$ \\
\hline $0(0 \%)$ & PET & 67 (8\%) & PET & \\
\hline 1987 (51\%) & Brain & 433 (55\%) & Brain & $22 \%$ \\
\hline 998 (21\%) & Neck & $235(30 \%)$ & Neck & $24 \%$ \\
\hline 1256 (28\%) & Spine & 124 (16\%) & Spine & $10 \%$ \\
\hline
\end{tabular}

Outside studies typically require at least as much effort as consults on internal patient imaging studies. There is growing literature suggesting that such outside consults can and should be paid for. ${ }^{5-7}$

We did not count managerial, teaching and research activities, peer-review, and so forth, which are other important non-RVU activities in academic practices. Others ${ }^{8}$ have proposed systems to measure such types of non-RVU activities.

Table 2: Type of encounter for the non-RVU-generating activities Non-RVU-Generating Activities

\begin{tabular}{ll}
\multicolumn{1}{c}{ Non-RVU-Generating Activities } \\
\hline $\boldsymbol{n}=792$ & \multicolumn{1}{c}{ Studies } \\
\hline $437(55 \%)$ & Conferences \\
$78(10 \%)$ & $1-$ on-1 \\
$218(28 \%)$ & E-mail/phone \\
$59(7 \%)$ & Electronic medical record consults \\
$541(68 \%)$ & Internal patients \\
$251(32 \%)$ & Outside studies \\
\hline
\end{tabular}

\section{DISCUSSION}

Our study describes an easy-to-implement method to record non-RVU-generating activities performed by clinically active academic neuroradiologists. During a 3-month representative time frame, non-RVU-generating studies comprised 19\% of the volume of the RVU-generating imaging studies, a significant fraction of the clinical effort of our neuroradiologists. This finding is in line with the results of a survey conducted in Ireland that showed that approximately one-third of radiologists' time is engaged in activities not easily counted in study numbers. ${ }^{4}$ Differences in absolute numbers could relate to our study having involved only 4 radiologists in 1 section of 1 academic institution. Most interesting, the $19 \%$ ratio of non-RVU activities to RVU reads was relatively constant for each of the 4 neuroradiologists and indicated that the neuroradiologists reading the most RVUs also performed the most non-RVU-generating consults and conferences. This indication suggests that our findings may hold independent of the academic time received by the neuroradiologists and may be representative of other neuroradiology sections at other academic institutions or in private practice.

We did not track the amount of time spent on individual consults or in preparing for conferences or tumor boards; hence, the time could be even greater, given the detailed interactions that often take place for each consult as well as follow-up communications and other postconsultation tasks. In addition, recording time accurately is a difficult task. We used RVUs as the basis for our recording because we wanted a very simple recording system that would not add significant burden or consume a significant amount of time for the participating radiologists. There had been prior attempts to record times, and the time measurements were variable and unreliable. The RVU recording is more representative, probably also because our activity is typically measured in RVUs.
Finally, we focused our attention on neuroradiology and did not examine other radiology subspecialties.

\section{CONCLUSIONS}

We developed a simple Web-based smartphone app to record and quantify non-RVU-generating activities, including consults, clinical conferences, and tumor boards, and we report the results of our consultation tracking via this app for 3 months. The quantification of non-RVU-generating activities is paramount in this time of a paradigm shift from volume to value. It also represents an important tool for determining staffing levels, which cannot be performed solely on the basis of RVUs, considering the value brought to the institution by radiologists involved in non-RVUgenerating consult activities. Studies such as this may influence payment models from medical centers to radiology departments or practices.

Disclosures: Max Wintermark—UNRELATED: Board Membership: GE Healthcare and National Football League Advisory Board. Greg Zaharchuk-UNRELATED: Grants/ Grants Pending: National Institutes of Health, ${ }^{*}$ GE Healthcare. * *Money paid to the institution.

\section{REFERENCES}

1. Lu Y, Zhao S, Chu PW, et al. An update survey of academic radiologists' clinical productivity. J Am Coll Radiol 2008;5:817-26

2. Burwell SM. Setting value-based payment goals: HHS efforts to improve U.S. health care. $N$ Engl J Med 2015;372:897-99 CrossRef Medline

3. Burleson J. Quality and the physician value-based payment program. Radiol Manage 2014;36:14-20; quiz 22-23 Medline

4. Brady AP. Measuring Consultant Radiologist workload: method and results from a national survey. Insights Imaging 2011;2:247-60 CrossRef Medline

5. Jeffers AB, Saghir A, Camacho M. Formal reporting of second-opinion CT interpretation: experience and reimbursement in the emergency department setting. Emerg Radiol 2012;19:187-93 CrossRef Medline

6. Zan E, Yousem DM, Carone M, et al. Second-opinion consultations in neuroradiology. Radiology 2010;255:135-41 CrossRef Medline

7. Briggs G, Flynn P, Worthington M, et al. The role of specialist neuroradiology second opinion reporting: is there added value? Clin Radiol 2008;63:791-95 CrossRef Medline

8. Mezrich R, Nagy PG. The academic RVU: a system for measuring academic productivity. J Am Coll Radiol 2007;4:471-78 CrossRef Medline CrossRef Medline 